\title{
Erratum to: Process modeling and parameter optimization using radial basis function neural network and genetic algorithm for laser welding of dissimilar materials
}

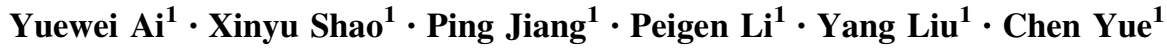

Published online: 17 September 2015

(c) Springer-Verlag Berlin Heidelberg 2015

\section{Erratum to: Appl. Phys. A DOI 10.1007/s00339-015-9408-5}

The original version of this article unfortunately contained mistakes.

The presentation of Fig. 12 and Table 9 was incorrect. A sentence in Sect. 4.1 showed wrong data. The correct Fig. 12 and Table 9, and sentence are given below.

From Table 9, the optimal $F$ is 232.041 , and the corresponding feasible solution value is 235.35 , and the error between them is $-1.43 \%$.

The original article was corrected.

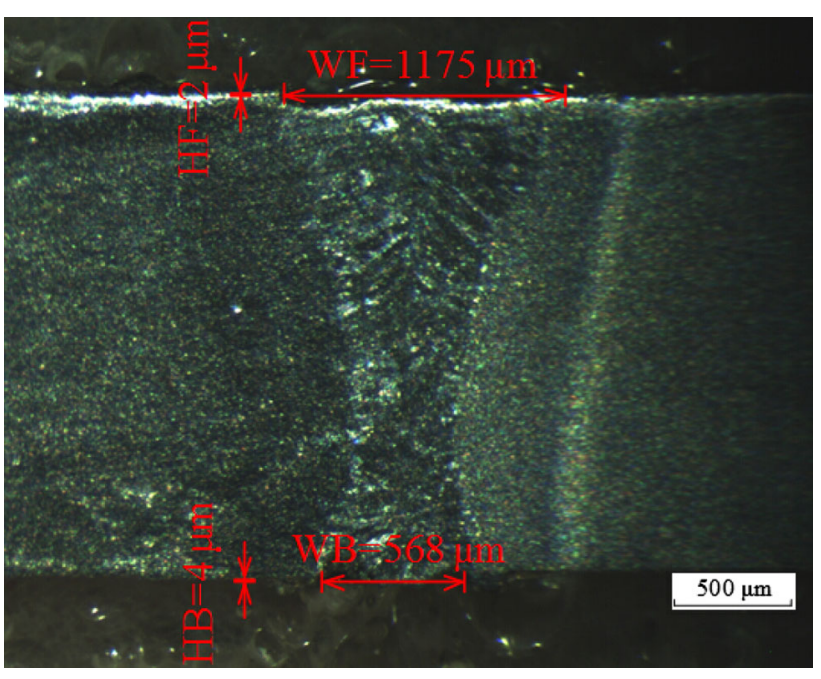

Fig. 12 The cross section of the weld seam generated by optimized parameters

The online version of the original article can be found under doi:10.1007/s00339-015-9408-5.

Ping Jiang

jiangping@mail.hust.edu.cn

1 The State Key Laboratory of Digital Manufacturing Equipment and Technology, School of Mechanical Science and Engineering, Huazhong University of Science \& Technology, Wuhan 430074, People's Republic of China 
Table 9 Confirmation test results

\begin{tabular}{|c|c|c|c|c|c|c|c|c|c|}
\hline Algorithm & $\mathrm{F}(\mu \mathrm{m})$ & $\mathrm{WF}(\mu \mathrm{m})$ & $\mathrm{HF}(\mu \mathrm{m})$ & $\mathrm{WB}(\mu \mathrm{m})$ & $\mathrm{HB}(\mu \mathrm{m})$ & LP (W) & $\mathrm{WS}(\mathrm{m} / \mathrm{min})$ & $\mathrm{FP}(\mathrm{mm})$ & GAP $(\mathrm{mm})$ \\
\hline Optimal solution (RBFNN-GA) & 232.041 & 1178.378 & -1.851 & 530.741 & 3.897 & 2500.974 & 3.491 & -0.856 & 0.021 \\
\hline Feasible solution & 235.35 & 1175 & -2 & 568 & 4 & 2500 & 3.5 & -1 & 0.02 \\
\hline Err $(\%)$ & -1.43 & 0.29 & -8.05 & -7.02 & -2.64 & - & - & - & - \\
\hline
\end{tabular}

Err error $=[($ Optimal solution $)-($ Feasible solution $)] /($ Optimal solution $) \times 100 \%$ 